\title{
Research on the Strategy of Improving the Quality of Classroom Teaching -Study on the Perspective of Learning Science Theory
}

\author{
Cuiying $\mathrm{Li}^{1, \mathrm{a}^{*}}$, Yi Cheng ${ }^{2, \mathrm{~b}}$ and Yue Kang ${ }^{2, \mathrm{c}}$ \\ ${ }^{1}$ College of Educational Reform and Teaching Quality Evaluation Center, Bohai University, Jinzhou \\ 121013, China \\ ${ }^{2}$ College of Mathematics and Physics, Bohai University, Jinzhou 121013, China \\ aLncy999@126.com, bchengyi4070@126.com, 'cm18041366321@163.com
}

Keywords: Learning science; Teaching reform; Research methods; Classroom teaching

\begin{abstract}
The aim of education reform is to improve the quality of classroom teaching, allow learners to learn more knowledge and skills in an effective period of time. Since the promulgation and implementation of the "national education plan", a series of achievements have been made in improving the quality of classroom teaching. In this paper, from the perspective of learning science, combined with the actual situation of classroom teaching, in view of the existing classroom teaching method is single, old teaching ideas, the teaching effect is not ideal and so on, explore the strategies to improve the quality of classroom teaching, truly "to the quality of the classroom", the research and improvement of classroom teaching methods, further improve the quality of teaching.
\end{abstract}

\section{Research Background}

"Learning Sciences " is a cross disciplinary research field developed in the last 30 years in the world, see [1-7]. It is emerging of a discipline based on cognitive science, psychology,education, brain science,neurology and so on, in view of the complexity of learning, a variety of scientific research methods from different vision, study all kinds of situations, as well as a comprehensive understanding of personal and social cognition, easy for teachers to better design the classroom, help learners improve their learning efficiency, provide theoretical and practical guidance for the effective improvement of the quality of classroom teaching.

Learning science at the end of 1970s, researchers have begun to explore the nature of human learning, some of the relatively unique methodology. Gradually mature after 1990s, start as an independent discipline area stand out, to the dawn of twenty-first Century, learning science as a new discipline has begun to affect the classroom teaching, out of school education, learning product design , learning organization design ,teacher education, occupational training school, a series of changes and innovation in many aspects.

In many developed countries, learning science has been explicitly included in the educational policy, the result of the research has a profound influence on the educational reform, see [8-10]. In the course of teaching and learning, learning science has become a new path to improve the quality of classroom teaching in many developed countries.

In China, many colleges and universities have already established the research institutions of learning science, the convergence of the three forces of cognition, design and social context, combine teaching environment, innovative curriculum and classroom activity structure, to explore the psychological and social process of learning, establish a model to improve the quality of classroom teaching, so that the learners can effectively get the knowledge and skills of the organization.

\section{Strategies For Improving the Quality of Classroom Teaching Based on the Theory of Learning Science}

Training Teachers to Learn Scientific Literacy. The reform of teaching is the first of all. Traditional teaching methods are hard to be taught by teachers and students to listen to, this passive teaching mode is not conducive to the cultivation of students' ability of independent thinking and 
analysis and judgment, it is difficult to stimulate students' interest in learning, can't reach very good teaching effect. Teachers in Colleges and universities to help, coordinator, facilitator role in education and teaching activities, to provide a suitable environment for students' learning and development, cultivating the learning ability of College Students, oneself must change the traditional teaching idea and the teaching thought, have a good learning science literacy. Study the teaching idea and the teaching level of the teachers' teaching process. Simply say that teachers should have the learning science literacy is mainly to understand how the brain is learning, how students learn, need to design learning environment according to the characteristics of their own teaching. "How to learn" is often restricted to "how to teach". Once teachers understand how students learn, can help learners to learn more effectively, enhance their learning ability.

Focus on Teaching Security. Schools can provide a wealth of learning resources. Deepening the reform of classroom teaching in Colleges and Universities, upper protection to keep up with, schools should provide a variety of learning resources and tools, mainly have: various hardware facilities, full book resources, all kinds of learning software and so on, it is very important for college students to study, such as computers for students' learning, Electronic Reading Room, Virtual Laboratory, learning website, a variety of experimental equipment, all kinds of paper books and all kinds of electronic texts, graph,frequency, video, animation and so on which is relate to all kinds of electronic resources about learning, encourage college students to use technology to support learning, improve learning efficiency.In addition, provide comfortable and pleasant, with a good cultural heritage for college students to learn the campus environment, etc.

The educational administration department sets up the course of teaching. Teaching reform in any case, can not be separated from the curriculum settings, curriculum setting plays an important role in the cultivation of College Students' learning ability. From a longitudinal perspective, it is to pay attention to the longitudinal interaction between the course, to think about the logical relationship between the four years of college and university courses,step by step to set course. From a horizontal perspective, consider the position and function of basic knowledge, professional knowledge and professional knowledge in the system of professional knowledge, knowledge of the key and difficult to organize the course, to make students master the theoretical framework and logical framework of the subject.Meanwhile, attach importance to practical lesson. The practice of curriculum should not only be regarded as the supplement and dependency theory course, it is an important part of the university curriculum which is complementary to the theory course, students learn a lot of practical skills in specific practical action, these are the theoretical courses can not be done.

Encouraging teachers to actively participate in teaching ability training, in the teaching reform, the teachers should pay attention to the quality of training for all teachers to provide a wide range of learning opportunities, regular teacher training teachers play an important role in the cultivation of students' learning ability. The good quality of teachers helps to cultivate the students' ability, teachers do not have a wealth of professional knowledge, good education and teaching knowledge, also can be very good in teaching activities, know how to use their professional knowledge and teaching knowledge in the situation. When training, should pay special attention to practical knowledge, training teachers' practical teaching skills.Besides, the teachers should be combined together, establishment of teacher learning community, so that they can learn from each other.

Schools should consider setting up a "learning science" course and also consider setting up a "learning science" curriculum, through the course study, make college students understand: how the brain studies, what is the cognitive mechanism, what kind of learning environment is the most conducive to the study of the brain, how to shape their own brain to become a good learning ability of the brain, how people learn, what is the characteristic of knowledge, what kind of knowledge is most valuable, how to learn in order to acquire valuable knowledge, what kind of learning environment is the most suitable for learning, what kind of support is needed in the process of learning, how to use technology to support their own learning and a series of scientific knowledge and learning, only in this way, can form a correct view of knowledge and learning, in order to understand the basis of 
knowledge and learning, better control of their own learning, conscious of the weaknesses in the study, to cultivate their learning ability.

Design Strategies for Classroom Teaching of Teachers. As the saying goes, the good beginning is half the success.Have a good first class, left a deep impression on the students, establish a good relationship between teachers and students, establish a good relationship between teachers and students, stimulate students' interest in learning, to lay the foundation for the future development of classroom teaching. In the first class, don't rush to teach the knowledge learned in the classroom, direct entry into teaching, can guide the students to understand and master the course of the relationship between the social significance and personal, know why you learn, induce students to ask some questions about the course, inspire students to learn the consciousness. At the same time to show that teachers and students are equal relations, respect each other in future studies, as much as possible to meet the needs of the majority of students and so on. All this will inspire the enthusiasm of the students, it is play a positive role in promoting for the teaching of teachers in the future.

In the teaching process, we should constantly update the teaching methods and means. Teachers in the teaching process should be correct and appropriate use of some modern teaching methods, the shape, sound and color combination to make the teaching content more intuitive,image,vivid,reality, more can stimulate students' learning interest, moreover,in the teaching practice, explore and try all kinds of heuristic teaching methods which are suitable to the teaching level, improve the learning initiative and enthusiasm.For example, in the classroom teaching can be interspersed with questions, situation teaching, teacher-student activities and other links. The same class, using a variety of teaching methods and teaching methods, can make the boring classroom lively and interesting, avoid the students' atmosphere in class, learning efficiency is not high.

Teaching students in accordance with their aptitude- to guide students to choose their own learning methods and to make a special emphasis on scientific research in the middle school, let the students through personal experience to obtain knowledge. This kind of learning strategy is suitable for students who like to study, they include not only knowledge and skills in scientific inquiry, but also the way of inquiry,ability,scientific attitude,emotion, sense of worth and other issues related to the actual life of the students themselves. Learning by doing is not only emphasis put on the students to connect the scientific knowledge they have with the scientific knowledge they have gained from the multi-channel, but also apply the scientific content of the science to the new problem solving, let the students experience the process of scientific exploration, comprehensively improve students' Scientific Literacy.

Problem based learning is a kind of advanced learning strategy and teaching method which is widely used in foreign countries, it is consistent with the idea that quality education in our country , comprehensively improve the basic quality of studentsis based on the principle of educating people, reflects the characteristics and requirements of quality education. Problem based learning is based on information processing psychology and cognitive psychology, belongs to the category of constructivism learning theory, this is a kind of learning experience, an investigation and search for a solution to a problem that is not clear about the structure of real life. It emphasizes that knowledge learning is set up in a complex and meaningful problem situation, through the efforts of the learning community, to learn the scientific knowledge hidden behind the problem, skills to solve problems, and the ability to form independent learning.

We guide students to use technology to learn independently and know that technology can be used as a support and tool to help students solve problems, the use of technology, it can make the students get the necessary learning resources, peer information, demonstrate their learning outcomes and so on, more can stimulate the learning interest of the learner. Through modern technology such as computer, network, etc, tools to make abstract knowledge concrete, try to apply the learned knowledge to the specific situation, to promote students' deep understanding, to enhance their ability to apply their knowledge.

Creating a learning environment is suitable for students' learning ability. Design suitable learning environment is conducive to the learning of students, can enhance the learning ability of College 
Students. Teachers should be good at using all the resources around for the students to create the use of knowledge, learning the knowledge of the situation. This scene can not only happen in the classroom and school,but also happen outside the classroom, to provide students with a knowledge of the scene, enable learners to connect the previous experience, knowledge and context, to stimulate learners' interest in learning, help the learners to understand the knowledge, improve their ability to use knowledge, in order to improve the ability to solve problems.

Emphasizing student center status, students are the subject of study, the teaching must take the student as the center to carry on the classroom instruction design. Teaching in the design of learning environment, students should take full account of prior knowledge, social experience, cultural background and so on, set specific situations, put forward some personal problems which are meaningful to the students, relate the knowledge and concepts of the required learning to the student's previous experience, lead them to understand new knowledge and concepts by using previous experience give full play to the main role of students in classroom teaching.

Emphasizing on knowledge reorganization, learning is not a mechanical memory, not to transfer knowledge from an expert to a novice, it is a process of active construction of learners, students need to take the initiative to engage in related practice, with their own emotions, feelings, experiences, lessons learned and knowledge of the dialogue, cognitive processing of materials they are learning with the knowledge that has been learned., create a new relationship between knowledge and new learning materials to find the value of knowledge, spiritual freedom,the meaning of life and development direction.

\section{Acknowledgments}

Research is supported by the NNSF of China (No.11401042, 11301541) and the Five-Year planning of higher education research of higher education institute of Liaoning Province (No.GHYB160080).

\section{References}

[1] P. X. Ning, Y. Ying. AP science project development and reform of science curriculum in high school in China. Theory and Practice of Education, 8(2009)8-10.

[2] Bransford, K. Cheng la et al translation, How people learn: brain, psychology, experience and school Shanghai: East China Normal University Press, 2002, pp.17-18.

[3] National Research Council. Learning Science in Informal Environments: People, Places, and Pursuits. http://www.nap.edu/catalog/12190.htm1.2009[2010-08-02].

[4] R. Sawyer Keith. Cambridge Handbook of learning science. Beijing: Educational Science Publishing House, 2010.

[5] D. Q. Huang, Y. M. Jia, Study on the development of American learning science Studies in foreign education, 38(2011)91-96.

[6] J. Kolodner, The Learning sciences: Past, present, future [J]. Educational Technology, 5(2004)34-40.

[7] J. Kolodner, The "neat" and the "scruffy" in promoting learning from analogy: we need to pay attention to both. The Journal of the learning Sciences, 11(2002)139-152.

[8] R. Mayer, Introduction to multimedia learning. In Mayer, R. The Cambridge Handbook of Multimedia Learning. Cambridge University Press, 2005.

[9] Polman, Dialogic activity structures for project-based learning environments. Cognition and Instruction, 22(2004)431-466. 
[10] M. C. Linn, Designing computer learning environments for engineering and computer science: The scaffolded knowledge integration framework, Journal of Science Education and Technology, 4(1995)103-126. 